\title{
Research on investment risk assessment of Eco-materials Industry
}

\author{
Hongxia Jin ${ }^{1, a}$, Heping $\mathrm{YaO}^{2, \mathrm{~b}}$, Jie $\mathrm{Yu}^{3, \mathrm{c}}$ \\ ${ }^{1,3}$ Business School of Hebei Agricultural University, No.289 LingYu-Temple Street Baoding City \\ Hebei Province China 071001 \\ ${ }^{2}$ College of Humanities of Hebei Agricultural University, No.289 LingYu-Temple Street Baoding City \\ Hebei Province China 071001 \\ ajinhx2008@163.com, bheping@hebau.edu.cn
}

Keywords: Eco-materials industry, Venture Capital, risk assessment, rough sets, SVM.

\begin{abstract}
With the rapidly deteriorating of ecological environment and depletion of resources, construction investment of eco-materials industry is gradually increasing, so the investment risk assessment has become a hot research problem at present. In this paper, a new investment risk assessment system for eco-materials industry is presented, which combines rough set approach and support vector machine (SVM). It is different from traditional statistical methods. We can get reduced information table by rough set, which implies that the number of index and qualitative variables is reduced with no information loss by rough set approach. And then, this reduced information is used to develop classification rules, and SVM is trained to infer appropriate parameters. The result of the positive research indicated that this system is very valid for investment risk assessment of eco-materials industry and it will have a good application prospect in this area.
\end{abstract}

\section{Introduction}

As a serious threat to human survival, which restricts the development of socio-economic, and a major crisis which human survival and development is facing in the 21st century, shortage of natural resources and deterioration of ecological environment has become one of the focus that international community widespreadly concern. However, social and economic development is supported by a large number of various types of raw materials. Therefore, the resource-saving and environment friendly development of materials and their industry has becoming the material foundation for sustainable development of social and economic, eco-materials are also researched and universally applied, and project investment of eco-materials is gradually increasing. Morerover, investment risk of eco-materials industry is very high, and facing a variety of objective or subjective factors, so it is possible to extension, suspension, fail or fail to achieve the technical and economic indicators of project investment due to the occurrence of risk events. Therefore, how to assess eco-materials project investment risk has become an urgent and important issues.

In this paper, an investment risk assessment model has been proposed which is composed of rough set component and SVM component. On the one hand, rough set theory has been proved to be very effective in dealing with uncertainty or imprecise information. By rough sets, some deterministic rules are extracted from the information system. On the other hand, SVM can capture the geometric characteristics of feature space without deriving weights of networks from the training data and it is capable of extracting the optimal solution with small training data, which is on the basic that the investment risk assessment index system of eco-materials industry is established in modern enterprise.

\section{Model Construction and experiment based on Rough sets and SVM}

\section{Research data and index terms}

The research data we employ is provided by Chinese eco-materials industry dataset in 2010, the sample data sets consist of the equal indications. To begin with, We selected six Chinese eco-materials as assessment samples, these samples are based on the following factors: technology risk, market risk, management risk, external environment risk, financial risk and exit risk. In addition, 
we choose twenty-one indexes as the training data (Table1). These indexes are based on economic and social factors, which distinguish between investment risk of eco-materials industry.

Table 1 the investment risk assessment index system of eco-materials industry

\begin{tabular}{|l|l|}
\hline Technical risk & $\mathrm{x}_{1}$ technical originality, $\mathrm{x}_{2}$ technical advancement, $\mathrm{x}_{3}$ technical reliability, $\mathrm{x}_{4}$ technical practicality \\
\hline Management risk & $\begin{array}{l}\mathrm{x}_{5} \text { management team skills, } \mathrm{x}_{6} \text { innovation capacity, } \mathrm{x}_{7} \text { managers quality, } \mathrm{x}_{8} \text { measures and extent of } \\
\text { excitation }\end{array}$ \\
\hline Market risk & $\mathrm{x}_{9}$ market demand; $\mathrm{x}_{10}$ market size; $\mathrm{x}_{11}$ network of market sales $\quad \mathrm{x}_{12}$ commercial credibility \\
\hline Financial risk & $\mathrm{x}_{13}$ repay ability; $\mathrm{x}_{14}$ profitability; $\mathrm{x}_{15}$ financing ratio; $\mathrm{x}_{16}$ owner's equity-to-income ratio \\
\hline environmental risk & $\mathrm{x}_{17}$ influence national policy; $\mathrm{x}_{18}$ macroeconomic environment; $\mathrm{x}_{19}$ natural environment \\
\hline Exit risk & $\mathrm{x}_{20}$ exit channels; $\mathrm{x}_{21}$ exit rate of return on capital \\
\hline
\end{tabular}

Weight allocation of the qualitative indexes has much influence on the evaluation result, and determining the weight vectors accurately, objectively effects the risk appraisal of enterprises' technological innovation directly. So it is very important. The paper introduces two methods in order to offer the alternatives in practical application:

(1) The method of AHP and its application in Matlab6.x. The analytical hierarchy process is a multi-goal decision-making method with combining qualitative analysis and quantitative analysis.

(2) The method with combining Delphi and FAHP. Consult the experts and enterprise operators repeatedly, ask them to judge the relative importance degree between every two factors in $\left\{u_{1}, u_{2}, \cdots, u_{k}\right\}$, and then get fuzzy consistent matrix $R=\left(r_{i j}\right)_{k \times k}$. Here, set the weight vector of $\left\{u_{1}, u_{2}, \cdots, u_{k}\right\}$ is $\left\{a_{1}, a_{2}, \cdots, a_{k}\right\}$, the following weight equation group can calculate the weight value:

$$
\text { Eq. } 1\left\{\begin{array}{c}
2 \beta^{2}(k-1) a_{1}-2 \beta^{2} a_{2}-2 \beta^{2} a_{3}-\cdots-2 \beta^{2} a_{k}+\lambda=\beta \sum_{j=1}^{k}\left(r_{1 j}-r_{j 1}\right) \\
-2 \beta^{2} a_{1}+2 \beta^{2}(k-1) a_{2}-2 \beta^{2} a_{3}-\cdots-2 \beta^{2} a_{k}+\lambda=\beta \sum_{j=1}^{k}\left(r_{2 j}-r_{j 2}\right) \\
\cdots \\
-2 \beta^{2} a_{1}-2 \beta^{2} a_{2}-2 \beta^{2} a_{3}-\cdots+2 \beta^{2}(k-1) a_{k}+\lambda=\beta \sum_{j=1}^{k}\left(r_{k j}-r_{j k}\right) \\
\cdots \\
a_{1}+a_{2}+\cdots+a_{k}=1
\end{array}\right.
$$

Hereinto, $\lambda$ is Lagrange multiplier, and $0<\beta \leq 0.5$. $\beta$ means the difference degree of people perceiving an object and is positive correlation with the number of the object and the difference degree. And then, the other method is adopted to make sure the appraisal value of each beginning index, finally, the basic fifteen risk evaluation datum are cleaned up.

\section{Attribute reduction based on rough sets}

Rough set analysis part of the experiment was performed by Rosetta developed by Norwegian Scientific and Technological University and Portland Warsaw University[6,8]. After rough set analysis was performed, as we can see, in 10 experiments one minimal reduction is obtained composed of eleven indexes: $\left\{x_{1}, x_{2}, x_{5}, x_{7}, x_{9}, x_{10}, x_{12}, x_{13}, x_{15}, x_{18}, x_{21}\right\}$, according to the procedure of rough sets method.

\section{Experiment and results based on SVM}

SVM was used to settle the problem of pattern recognition, the generalized performance is realized by the classing algorithm, with the insensitive loss introduced by Vapnik[5], the SVM has been extend to solve the nonlinear regression. In experiment, the polynomial kernel and the Gaussian radial basis function are used as the kernel function of SVM.

Table 2 Result after SVM analysis

\begin{tabular}{|c|l|l|l|l|l|l|}
\hline \multirow{2}{*}{ Experiment } & \multicolumn{3}{|c|}{ Group I } & \multicolumn{3}{c|}{ Group II } \\
\cline { 2 - 7 } & $\mathrm{N}^{\mathrm{a}}$ & $\mathrm{D}^{\mathrm{b}}$ & $\mathrm{W}^{\mathrm{c}}$ & $\mathrm{N}$ & $\mathrm{D}$ & $\mathrm{W}$ \\
\hline 1 & 0.90 & 0.82 & 0.93 & 0.14 & 0.27 & 0.12 \\
\hline 2 & 0.85 & 0.86 & 0.92 & 0.21 & 0.18 & 0.07 \\
\hline 3 & 0.85 & 0.72 & 0.85 & 0.05 & 0.14 & 0.08 \\
\hline 4 & 0.86 & 0.73 & 0.87 & 0.14 & 0.27 & 0.13 \\
\hline 5 & 0.90 & 0.91 & 0.94 & 0.1 & 0.09 & 0.06 \\
\hline
\end{tabular}




\begin{tabular}{|c|c|c|c|c|c|c|}
\hline 6 & 0.88 & 0.85 & 0.94 & 0.12 & 0.15 & 0.06 \\
\hline 7 & 0.79 & 0.79 & 0.88 & 0.21 & 0.21 & 0.14 \\
\hline 8 & 0.86 & 0.73 & 0.88 & 0.15 & 0.19 & 0.14 \\
\hline 9 & 0.79 & 0.81 & 0.86 & 0.10 & 0.16 & 0.09 \\
\hline 10 & 0.95 & 0.84 & 0.91 & 0.15 & 0.28 & 0.17 \\
\hline \multicolumn{7}{|c}{ Normaliy ${ }^{\mathrm{b}}$ Doubt ${ }^{\mathrm{C}}$ Warning } \\
\hline
\end{tabular}

Table 3 The results of classification in Group I were compared

\begin{tabular}{|c|l|l|l|l|l|l|}
\hline Experiment & \multicolumn{3}{|c|}{ BPN } & \multicolumn{3}{c|}{ SVM } \\
\hline & L & M & H & L & M & H \\
\hline 1 & 84.5 & 88.5 & 82.2 & 84.6 & 95.8 & 86.4 \\
\hline 2 & 81.7 & 82.9 & 85.9 & 89.6 & 92.7 & 85.7 \\
\hline 3 & 83.2 & 85.7 & 81.3 & 88.3 & 89.3 & 88.5 \\
\hline 4 & 85.6 & 87.7 & 81.6 & 90.2 & 94.5 & 88.4 \\
\hline 5 & 84.7 & 85.4 & 85.9 & 89.3 & 96.6 & 84.8 \\
\hline 6 & 80.2 & 87.3 & 85.1 & 92.1 & 91.8 & 87.2 \\
\hline 7 & 86.3 & 86.8 & 83.7 & 93.5 & 95.1 & 81.4 \\
\hline 8 & 80.2 & 86.4 & 83.5 & 83.2 & 92.6 & 88.8 \\
\hline 9 & 81.6 & 87.8 & 83.7 & 84.6 & 95.1 & 86.7 \\
\hline 10 & 84.2 & 83.1 & 84.7 & 85.7 & 95.8 & 87.1 \\
\hline Average & \multicolumn{3}{|c|}{80.89} & \multicolumn{5}{|c|}{88.56} \\
\hline
\end{tabular}

Table 4 The results of classification in Group II were compared

\begin{tabular}{|c|l|l|l|l|l|l|}
\hline \multirow{2}{*}{ Experiment } & \multicolumn{3}{|c|}{ BPN } & \multicolumn{3}{c|}{ SVM } \\
\cline { 2 - 7 } & $\mathrm{L}$ & $\mathrm{M}$ & $\mathrm{H}$ & $\mathrm{L}$ & $\mathrm{M}$ & $\mathrm{H}$ \\
\hline 1 & 82.4 & 84.2 & 81.1 & 86.7 & 95.5 & 90.9 \\
\hline 2 & 81.5 & 88.9 & 80.0 & 89.5 & 93.8 & 80.0 \\
\hline 3 & 83.6 & 86.2 & 79.0 & 88.6 & 86.7 & 80.0 \\
\hline 4 & 84.4 & 92.6 & 76.9 & 87.4 & 92.6 & 84.6 \\
\hline 5 & 84.6 & 81.8 & 75.0 & 86.2 & 81.8 & 87.5 \\
\hline 6 & 80.6 & 85.7 & 85.7 & 88.6 & 92.9 & 85.7 \\
\hline 7 & 82.2 & 83.3 & 78.6 & 91.3 & 91.7 & 78.6 \\
\hline 8 & 81.9 & 86.4 & 81.8 & 85.6 & 94.7 & 81.8 \\
\hline 9 & 83.4 & 87.5 & 80.0 & 86.3 & 94.4 & 80.0 \\
\hline 10 & 86.3 & 80.0 & 80.0 & 90.1 & 93.1 & 86.7 \\
\hline Average & \multicolumn{3}{|c|}{80.89} & \multicolumn{4}{c|}{88.56} \\
\hline
\end{tabular}

Since SVM does not have a general guidance for determining the upper bound $\mathrm{C}$ and the kernel parameter $\sigma^{2}$, this study varies the parameters to select optimal values for the best prediction performance. At last, we take the choice of $\sigma^{2}=2.8, \mathrm{C}=56.8$ and $\varepsilon=0.01$, which can produced the best possible results according to the validation set [9]. The MATLAB SVM toolbox executed these processes. For verifying the applicability of SVM, we also design BP neural network (BPN) (7) as the benchmark. The network structure was 5-9-1 for input layer, hidden layer and output layer respectively. We used sigmoid function for activation and Liebenberg-Marquardt algorithm for learning. The BPN were executed MATLAB NN toolbox. we constituted Hybrid Model I with rough sets and BP network, and Hybrid Model II with rough sets and SVM.

After rough sets and SVM analysis was finished and holdout sample was separated into two groups, three classifications results are produced: high, medium and low(Tab.2). And then, we tested the performance of each methodology. First, two methods which consisted of BPN and SVM were tested with group I holdout sample (Tab.3). Next, two methods were tested with Group II sample (Tab.4). Because cases in Group II have no matching rules, rules cannot classify them.

\section{Conclusions}

In this paper, a new method to establish the investment risk assessment model of eco-materials indurstry is proposed, which is more validated than other methods and based on many domestic and international research findings. SVM has many advantages such as fairly simple but powerful strategy for improving the classification accuracy. Additional two important efforts are the setting of risk assessment intervals and accuracy. Also, the experiment results show the effectiveness of rough set approach as a rule generator in data digging and the classifier of SVM approach. Consequently, the model helps to disperse and control investment risk of eco-materials indurstry, and then advance the success rate of eco-materials indurstry investment.

\section{References}

[1] Nie Zuoren: Ecomaterials for Circular Society Materials China. 2009, 5, Vol.28, No.5

[2] Zhang Zhi-ping, Wang Ang: Ecological Environment Material Study Research Development. Ecological Environment, 2003(1):12-15

[3] Li Aimin, Sun Kangning: Development of Ecomaterials and Their Influence on Society. Silicate Bulletin. 2003, 5 
[4] Wang Cheng, Shi Huisheng: Ecomaterials and Sustainable Development. China Non-metallic Minerals Industry Guide. 2009, 6

[5]Carl Gold, Peter Sollish: Model selection for support vector machine classification. Neurcomputing. 2005,55:221-249

[6]Gawrys M, Sienkiekiewicz J: Rough set library user's manual. Institute of Computer Science Warsaw University of Technology. 1993

[7] R. Li, Z.-o. Wang: Mining classification rules using rough sets and neural networks. European Journal of Operational Research. 7(157):439-448

[8] Pawlak: Rough sets and intelligent data analysis. Information Science. 2002, 11(147): 1-12

[9] Dayan Manohar Sinalingam, Narenkumar Pandia: Minmal classification method with eorror correlation codes for multiclass recognization. International Journal of Pattern Recognization and artificial intelligence. 2005, 5: 663-680 